\title{
EL USO DE LA LENGUA EN EL DIARIO DE JUÁREZ Y SU REPERCUSIÓN EN LOS LECTORES
}

The use of language in El Diario de Juárez and its INFLUENCE ON READERS

MARGARITA SALAZAR MENDOZA ${ }^{1}$

\section{RESUMEN}

$\mathrm{M}$ últiples investigaciones han indagado sobre la relación entre pensamiento y uso de la lengua, a través del análisis de la riqueza léxica; esta es medible y explica mucho del ambiente y comportamiento social de una comunidad. Este trabajo tiene como objetivo examinar el uso de la lengua de quienes redactan en El Diario de Juárez, mediante el análisis de tres fragmentos relativos a notas periodísticas sobre el mismo asunto y de diferente autor. Asimismo, hacer hincapié en la influencia sobre el habla que este periódico, como parte de los medios de comunicación masiva, ejerce sobre el auditorio.

Palabras clave: lengua, escritura, vocabulario, riqueza léxica, El Diario de Juárez.

1 Universidad Autónoma de Ciudad Juárez. Correo: masalaza@uacj.mx 


\section{ABSTRACT}

Previous research has treated language as a reflection of modes of thought. There are ways to measure the use of words and, as results indicate, these help explain a community's environment and social behavior. This work examines the use of the language from those who write in El Diario de Juárez, by analyzing three fragments relating to journalistic notes about the same subject and from different authors. Also, this article emphasizes the influence on speech that this newspaper, and mass media, exerts on the readers.

Key words: language, writing, vocabulary, lexical wealth, Diario de Juárez.

\section{PRÓLOGO}

Las publicaciones periódicas, como los diarios, juegan un papel muy importante dentro de una comunidad. Lo ahí expresado circula en el ambiente social, por lo que es conveniente analizar contenidos y formas, ya que tanto lo dicho como las palabras con las cuales se diga, serán una influencia inevitable en los receptores directos, los lectores, y en los indirectos, con quienes se comunican los primeros. Por ejemplo, un padre lee el periódico y lo que lea será su tema de conversación con sus hijos adolescentes o jóvenes. Por otra parte, los periodistas, "En su tarea diaria, construyen noticias en un proceso que supone incluir, excluir y jerarquizar ciertos hechos en las agendas informativas, no solo en función de criterios de noticiabilidad, sino también a partir del trazado de estrategias orientadas al logro de [otras] metas" (Califano, 2015, p. 61), como lo sostiene Bernadette Califano, quien agrega que "Los medios de comunicación desempeñan un papel importante en el conocimiento de la realidad que forma parte de nuestra vida cotidiana" (2015, p. 62). Dicho de otra manera, de acuerdo con el cariz que un periodista le dé a un asunto o a un 
problema, ese será, en términos generales, el primer y a veces el único acercamiento a tal evento.

Ciudad Juárez ha atravesado durante las últimas dos décadas, por lo menos, por una terrible situación social. Además de los efectos que la constante violencia registrada ha causado en los habitantes de la ciudad, se ha deteriorado la calidad de vida de estos. Todos los espacios se han visto degradados, los escolares, los familiares, los políticos, aun los de entretenimiento, ya sean públicos o privados; nada escapa al deterioro contextual. Cierto es que ese tipo de eventos violentos se convirtieron en una situación nacional, pero también es cierto que las soluciones no solo vienen de la federación, también pueden ser propuestas y encontradas localmente.

Una situación dada, sobre todo hablando de una nada positiva realidad, no nace de la noche a la mañana, siempre tiene una causa; si esta no es reconocida y si además es agravada por otras circunstancias, entonces repercute en todos los ámbitos en los que se mueve el individuo. Esos escenarios pueden ser atendidos y, aunque requieren acciones a largo plazo, sí es posible que estas contribuyan a generar un ambiente social distinto, más educado, que propicie una mejor calidad de vida.

De ahí que los medios de comunicación masiva tengan un gran peso en el entorno en que se mueven, pues como bien sabemos, la moda se impone por repetición, y un vocablo determinado se pasa de boca en boca porque suena "diferente" y porque lo usan los que "saben”, en este caso, los conductores de televisión o los periodistas, ellos son los que escriben ¿no?, para eso estudiaron, piensa el amplio auditorio. Sin embargo, en un ambiente deficiente, por ejemplo en el escolar, no se obtienen nada más que resultados deficientes. Si se desea que un grupo eleve su nivel de conocimientos debe estar expuesto constantemente a más conocimientos. Y así como los padres primero, y después los profesores, se erigen en un ejemplo de comportamiento, así los periódicos de la comunidad hacen lo propio. Si en una familia el léxico es pobre, así será el habla de los pequeños que ahí se formen. 
Tan importante es este asunto que existen diversos estudios semejantes al presente, como el de Eliana Martínez Valencia, quien se fijó como objetivo principal en su trabajo "analizar el léxico empleado en los titulares de prensa de uno de los periódicos colombianos" (2012, p. 211). Asimismo, Liliana Lombana y Soraya Valencia Treviño (2000) presentaron como su tesis de licenciatura en la Universidad del Valle, en Cali, Colombia, un estudio titulado Análisis semántico del léxico relacionado con la violencia utilizado en dos periódicos locales El País y El Caleño. Dentro de su investigación llevaron a cabo "una encuesta con 450 personas, mediante la cual se reveló el perfil del lector de tales periódicos, mismo que está relacionado con su grado de instrucción" (p. 74). De igual manera, pero en Bolivia, José Luis Gálvez Vera (2003) se interesó en el sensacionalismo buscado en las notas de los periódicos, mismo que de no buena manera repercute en los valores de los jóvenes, quienes quedan atrapados en una realidad específica, perversa, asegura Gálvez. Él termina cuestionando la libertad de prensa y el libertinaje en la información, que conducen a cuestiones éticas.

Para llevar a cabo esta investigación fue oportuno revisar tanto teorías lingüísticas como sociológicas. Entre las primeras está la teoría de Jean Piaget, que sostiene que el pensar se despliega a través de estímulos socioculturales, de tal manera que el pensar se forma por la cantidad de datos que el individuo recibe desde niño y que lo va formando, es decir, desde que el ser humano nace está expuesto de un modo activo, por más inconsciente y pasivo que parezca, a un cúmulo de información y que procesa de acuerdo con sus circunstancias contextuales e individuales. Así, los principios de la lógica se instalan en la mente del niño antes de la adquisición del lenguaje, mediante su interactuar con el medio familiar que lo cuida y le da una madurez específica, y después ampliándose a lo social. De tal suerte que la capacidad cognitiva y la inteligencia del ser humano se encuentran estrechamente ligadas al medio social y físico en el que se desenvuelve. Esto demuestra la capacidad de asimilación y la capacidad de acomodación que Piaget considera innatas en el hombre. 
Ya sea que el lenguaje se dé antes que el pensamiento o viceversa, surge un doble proceso, el idioma influye, determina la capacidad mental, es decir, el pensamiento se desarrolla gracias al desarrollo lingüístico del individuo, puesto que el lenguaje acelera nuestra actividad teórica, intelectual y nuestras funciones psíquicas superiores (percepción, memoria, pensamiento, etcétera). Así se explica en la teoría sobre la gramática generativa del lenguaje, propuesta desde 1957 por Noam Chomsky en su tesis doctoral Estructura lógica de la teoría lingüística.

Por otra parte, si el pensamiento está antes que el lenguaje teoría de la hipótesis cognitiva y de la cual el mayor representante es Jean Piaget-, entonces,

indica que el grado de asimilación del lenguaje por parte del niño, y también el grado de significación y utilidad que reporte el lenguaje a su actividad mental depende hasta cierto punto de las acciones mentales que desempeñe; es decir, que depende de que el niño piense con preconceptos, operaciones concretas u operaciones formales. (Richmond, 1981, p. 139).

Asimismo, una tercera teoría, la de simultaneidad, define que tanto el lenguaje como el pensamiento están ligados entre sí. Su mejor estudioso fue el ruso Lev Vigotsky (2005), quien explicaba que el pensamiento y el lenguaje se desarrollaban en una interrelación dialéctica. De todo lo anterior se desprende que el lenguaje, como lo dice A. Pétrovski (1979),

está particularmente ligado al pensamiento. Sin embargo, entre ellos no hay una relación de paralelismo, como frecuentemente consideran los lógicos y lingüistas tratando de encontrar en el pensamiento equivalentes exactos a las unidades lingüísticas y viceversa; al contrario, [...] el lenguaje es el instrumento del pensamiento (p. 205).

Por tanto, a una comunidad se le puede conocer y juzgar por su léxico y por su vocabulario. Un ejemplo muy sencillo de esta aseveración es la jerga de los adolescentes, que por sus propias 
particularidades de edad es entendida como "una característica propia de la contracultura”, según lo explica Jonnathan Salas Alvarado (2017, p. 184.), pues "es una forma de alejarse, hasta cierto punto, del control que puede ejercer [la autoridad] sobre ellos" (p. 197); pero a la larga tales individuos terminan por asimilarse a una de dos posiciones: la culta, que reditúa en prestigio intelectual, o la iletrada, que finalmente apaga la reflexión, la independencia en las decisiones, que propicia relaciones menos respetuosas y que incluso desvaloriza un hecho maravilloso, la vida. ${ }^{2}$

Asimismo, se pensó en cuál sería el arco temporal de la investigación, por lo que al considerar la cantidad de textos que se podrían analizar se optó por elegir un solo mes, pues ese periodo es suficiente para analizar y mostrar la clase de contenido y la forma de presentarlo. La riqueza léxica, por una parte, es obvia en un solo párrafo y por supuesto es más ilustrativa si se revisan notas completas y si se comparan entre ellas. Para efectos de lo buscado con este trabajo, cinco fragmentos de cien palabras dan como resultado una muestra del uso de la lengua. Por otra parte, en los resultados se expone el fondo de las noticias periodísticas y son más que notorios los aspectos éticos del contexto.

Entonces, se procedió a la captura de un mes completo de las notas publicadas por El Diario de Juárez, septiembre del año 2019, y únicamente de las secciones A y B, dedicadas a la ciudad. Después de su revisión cuidadosa se elaboraron algunas tablas en las que se clasificó el tipo de contenido. Posteriormente, se eligieron tres fragmentos en los que se revisó la riqueza léxica para ilustrar con ellos el uso que de la lengua se hace entre los periodistas que laboran en esa empresa; dichos fragmentos son los que aparecen en las primeras páginas de cada número, puesto que al ser "la cara” del día han puesto más cuidado, tanto en la redacción como en la edición y corrección de estos; además se consideró la misma clase de contenido para que sean comparables entre sí.

2 Los "jóvenes, al igual que cualquier otro ser humano, poseen la capacidad de modificar su registro en el momento y lugar en que lo estimen conveniente y estos cambios obedecen a muchas razones: en primera instancia, la jerga adolescente no cuenta con un prestigio lingüístico alto para la comunidad en general a pesar de que para los jóvenes posea un prestigio encubierto" (Salas, 2017, p. 197). 


\section{EL OBJETO DE ESTUDIO}

En la segunda década del siglo XXI, los títulos de prensa que han aparecido con regularidad en Ciudad Juárez pueden ser contados con los dedos de una mano. Hay tres periódicos impresos, negocio de empresarios locales -El Diario de Juárez (1976), ${ }^{3}$ Norte (1990) ${ }^{4}$ y Juárez Hoy (mayo de 2009). ${ }^{5}$ Esto no es de extrañar, Febvre y Martin nos recuerdan que en realidad "la imprenta no se estableció en América [Estados Unidos] durante el siglo XVIII mientras los impresores no descubrieron una nueva fuente de ingresos: el periódico" (1997, p. 211).

Por otro lado, se encuentra también el periódico PM (2005), un brazo de El Diario de Juárez, llamado así porque inicialmente se planteó como un vespertino; tanto fue su éxito que quienes toman las decisiones respecto a este cotidiano resolvieron que a media mañana ya estuviera en circulación. Su contenido es totalmente amarillista, pues explota el morbo que causan la violencia y las desgracias ajenas; incluye asimismo unas páginas centrales cuyas imágenes lindan con lo pornográfico, por supuesto, además de una amplia gama de publicidad.

Desde hace ya algunos años, y en realidad a exigencia de los tiempos, los periódicos de la región mantienen además de las ediciones impresas sitios electrónicos que les abren, según pregonan, un mercado amplio de lectores de todo el mundo. Desgraciada-

3 Osvaldo Rodríguez Borunda, quien lo fundó el 17 de febrero de 1976, es desde entonces su presidente y director general. Este diario se publica tanto en Ciudad Juárez como en El Paso, en donde comenzó a publicarse en el 2005, y hasta la fecha es el único medio que se edita en español todos los días en esa ciudad.

4 El lunes 3 de abril de 2017, Óscar Cantú Murguía, dueño del periódico Norte, anunció el cierre definitivo de la edición impresa que vio la luz durante 27 años.

5 Rafael Manuel Fitzmaurice Meneses es el fundador y director del periódico Juárez Hoy. Por cierto, las históricas instalaciones ubicadas en la Zona Centro, en la calle Vicente Guerrero entre Constitución y Bartolomé de las Casas, dejaron de albergar al emblemático XEJ TV Canal 5 local -del que también es concesionario y director Fitzmaurice Meneses-, para mudarse a la Teófilo Borunda, lugar donde se encuentran las instalaciones del periódico.

6 Explican Febvre y Martin que en la Norteamérica protestante casi no hubo ninguna imprenta durante el siglo XVII, sin embargo, entre 1691 y 1820 ocurrió una verdadera revolución: se publicaron no menos de 2120 periódicos, 461 de los cuales sobrevivieron más de 10 años (Febvre y Martin, 1997, pp. 208-211). 
mente, no brindan más de lo que han venido ofreciendo desde su nacimiento.

Ese tipo de publicaciones podría aportar algunos beneficios en lo que respecta a una visión crítica de la comunidad, toda vez que es un medio de comunicación que idealmente sintetiza, a través del trabajo de redacción y edición, la información generada por agencias de prensa, por periodistas o por los propios reporteros del rotativo. Al ser de una periodicidad diaria, la aparición recurrente de estas publicaciones constituye un excelente modo de llegar a un público amplio, lo que afirma la labor periodística. La mayoría de sus secciones informa no solo del acontecer local, sino de más allá de los límites del entorno del receptor. Precisamente por ello, algunas de sus secciones, como las editoriales, las de opinión y la de cultura podrían incidir en la formación del pensamiento de los lectores.

El Diario de Juárez está organizado en varias secciones, siete entre semana y ocho el domingo, tal como se desglosa en la Tabla 1.

Tabla 1. Organización del Diario de Juárez

\begin{tabular}{|l|l|}
\hline Sección A & $\begin{array}{l}\text { La sección A está fundamentalmente destinada a lo más } \\
\text { destacable, ya sea en la ciudad, en el estado o en el país, } \\
\text { incluso si la nota lo vale, puede aparecer en primera pla- } \\
\text { na un artículo de cariz internacional }\end{array}$ \\
\hline Sección B & Esta sección está dedicada a la ciudad \\
\hline Sección C & Deporte \\
\hline Sección D & Gente (espectáculos y gente de la farándula) \\
\hline Sección E & $\begin{array}{l}\text { Sociales (dedicada al registro de reuniones de la sociedad } \\
\text { juarense: quinceañeras, bodas, showers, graduaciones, } \\
\text { etc.) }\end{array}$ \\
\hline Sección F & Economía \\
\hline $\begin{array}{l}\text { Aviso } \\
\text { Clasificado }\end{array}$ & $\begin{array}{l}\text { Para venta de bienes muebles e inmuebles, así como para } \\
\text { ofrecer servicios. En ocasiones, esta parte está incluida } \\
\text { en la de Economía }\end{array}$ \\
\hline
\end{tabular}




\begin{tabular}{|c|c|}
\hline $\begin{array}{l}\text { Suplemento } \\
\text { Dominical }\end{array}$ & $\begin{array}{l}\text {-Compuesto básicamente de tiras cómicas (Popeye, Gar- } \\
\text { field, Pepita, Archie y otros) } \\
\text {-Asimismo, una parte de Opinión } \\
\text {-Además, folletos de publicidad de diversos centros co- } \\
\text { merciales y un fascículo de Empleos }\end{array}$ \\
\hline
\end{tabular}

Elaboración propia.

También, en fechas especiales se incluye un apartado dedicado a la fiesta en turno - como en septiembre a las Fiestas Patrias-, el que, sin embargo, solo contiene un pequeño artículo al respecto y que sirve de pretexto para sugerir un sinnúmero de lugares para el consumo. Sabido es de sobra que la publicidad es el motor de los periódicos, que sin ella difícilmente podrían sobrevivir.

Entre los resultados del análisis textual se apreció que, durante el mes de septiembre del 2019, en El Diario de Juárez se publicaron 363 notas en la sección A y 518 en la sección B, tal como se muestra en la siguiente tabla.

Tabla 2. Cantidad de notas publicadas por El Diario de Juárez en septiembre de 2019 en las secciones A y B, dedicadas a la ciudad

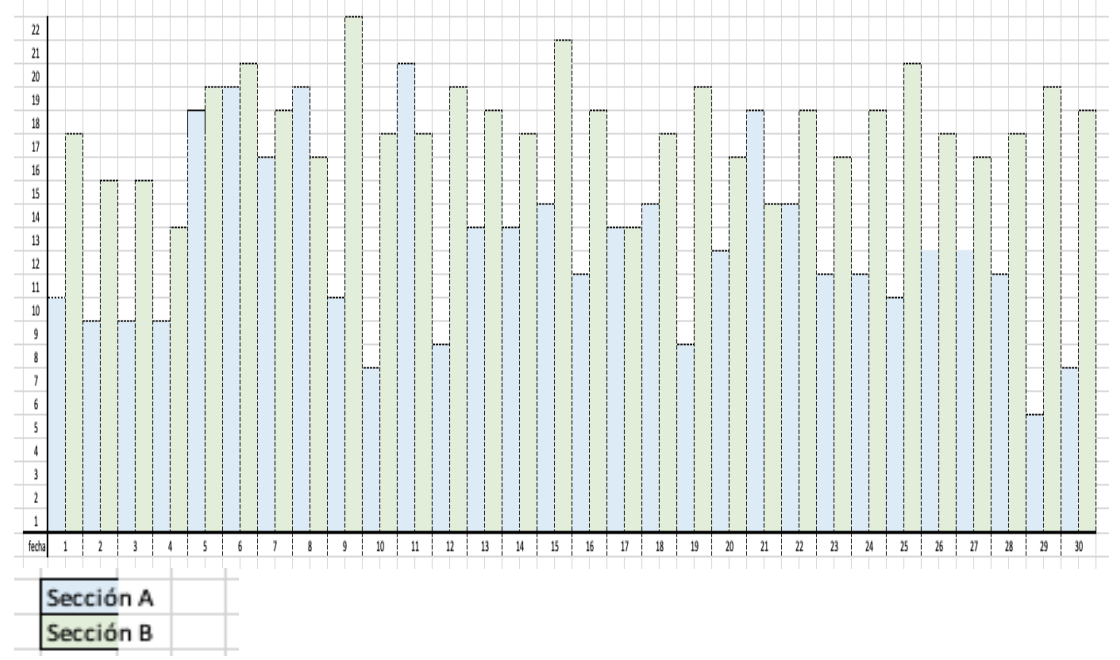

Elaboración propia. 
Se nota con claridad que en la sección A aparece una menor cantidad de notas que en la B; esto se debe a que el espacio disponible en la primera página del periódico está mayormente destinado a llamar la atención con, por ejemplo, grandes letras de los titulares, fotografías y el título y logo propios del diario.

Por otra parte, y de acuerdo con la Tabla 3, es notorio que predominan los asuntos relacionados con la delincuencia en general.

Tabla 3. Clasificación de notas por asunto tratado

\begin{tabular}{|c|c|c|c|}
\hline Actores & Asunto & Parcial & Total \\
\hline \multicolumn{3}{|l|}{ Infancia } & 33 \\
\hline & Descuido & 20 & \\
\hline & Reflexión sobre problemas & 8 & \\
\hline & Acciones en beneficio de & 5 & \\
\hline \multicolumn{3}{|l|}{ Drogas } & 27 \\
\hline \multicolumn{3}{|l|}{ Asesinatos } & 108 \\
\hline & $\begin{array}{l}\text { Hombres } \\
\text { Mujeres }\end{array}$ & $\begin{array}{l}89 \\
19\end{array}$ & \\
\hline \multicolumn{3}{|c|}{ Delincuencia } & 139 \\
\hline \multicolumn{3}{|l|}{ Ciudad } & 110 \\
\hline \multicolumn{3}{|l|}{ Escuelas } & 27 \\
\hline \multicolumn{3}{|l|}{ Política } & 67 \\
\hline & $\begin{array}{l}\text { Alcaldía } \\
\text { Otros }\end{array}$ & $\begin{array}{l}24 \\
43 \\
\end{array}$ & \\
\hline \multicolumn{2}{|l|}{ Total } & & 511 \\
\hline
\end{tabular}

Elaboración propia.

En total se publicaron 33 notas en cuyos hechos estuvieron inmiscuidos menores de edad, 20 que hablaban del descuido en que se vieron envueltos y 8 que reflexionaron en problemas de infantes; en contrapartida a esas noticias de sentido negativo, se publicaron 5 relativas a acciones en beneficio de la niñez.

Por otra parte, 27 de los registros se refieren al ambiente de las drogas, 108 trataron asesinatos (en otras palabras, muertes violentas), de los cuales 89 corresponden a actos cometidos contra 
hombres y 19 contra mujeres. 139 asuntos puestos a la luz trataron sobre delincuencia en general y 110 fueron dedicados a la ciudad por diversos asuntos. Solo hubo 27 cuestiones relativas a escuelas, 67 expusieron tópicos políticos y de ellos 24 fueron exclusivos del municipio y 43 variados, o sea, del estado o del país.

Los actos delictivos aquí agrupados no solo se refieren a cuestiones de riñas, pandillas, extorsiones y robo, sino que también se deben adjuntar las clasificadas en drogas, las notas sobre descuido de niños, las etiquetadas en asesinatos, incluso conductas cotidianas que sobrepasan los límites del buen trato social, como los escándalos en fiestas, la posesión ilegal de armas o lo que es peor, el maltrato familiar. Todos esos hechos conforman un ambiente y, como la gente de Ciudad Juárez lo sabe, no se puede calificar como un excelente escenario de bienestar para quienes en tal ciudad habitan.

Los números mostrados nos hablan por sí solos de la magnitud de algunos asuntos convertidos en problemas en la ciudad, por ejemplo, no son pocos los niños dejados a la deriva según la nota que afirma que "suman 5 casos de niños 'olvidados' en escuelas"; o los muy pequeños que vagan solos por las calles de la ciudad, como indica la nota del día primero titulada: "Hallan a niña de 3 años deambulando en la calle"; o los menores que al estar con adultos corren peligro -de acuerdo con una nota del domingo 16-: "Rescatan a niña cerca de canal; sus cuidadores estaban ebrios".

Entre el correcto o incorrecto actuar hay un espectro en cuyos extremos encontramos la conducta social conveniente y la francamente antisocial. Podemos decir en una analogía que dicha banda va del blanco al negro, en cuyo recorrido encontraremos una zona gris, menos gris o más gris según se acerque a una o a otra orilla. Esta zona gris, de acuerdo con Wil Pansters (2012, pp. 3-39) constituye el espacio donde suceden hechos velados, de los que no se sabe con precisión si deben ser sancionados. Ese estado de cosas tan generalizado se refiere a todas aquellas prácticas diarias que, aunque no son del todo ilícitas, sí causan perjuicio a 
terceros. Muchos actos de irresponsabilidad entrarían en ese rubro tan extendido.

Siguiendo las ideas de Pansters, existe una estrecha relación entre un ambiente social y los actos individuales. Uno de los criterios de la ya mencionada zona gris se refiere al espacio donde acaecen los hechos que por una u otra razón quedan ocultos, de los que no se conoce con precisión el responsable, pero de quien se rumora en general. Si tomamos solamente esas notas sobre descuido y abandono de niños, aunque no se sabe quién exactamente estaba a cargo de tales infantes, podría haber sido la madre, el padre, la abuela, algún tío, incluso una vecina, lo cierto es que alguien faltó a su compromiso y no hubo una sanción para tal negligencia, lo cual a la largo y por acumulación incide en la formación de los pequeños, poniéndolos en peligro real. ${ }^{7}$

Regresando a los resultados obtenidos de la revisión de El Diario de Juárez, la sección Opinión, que aparece solamente los domingos, este mes de septiembre estuvo construida como aquí se muestra:

Tabla 4. Sección Opinión

\begin{tabular}{|l|}
\hline \multicolumn{1}{|c|}{ (Dominical) } \\
\hline La Columna \\
\hline La vida de cuadritos \\
\hline \\
\hline Luis Javier Valero Flores \\
\hline Francisco Ortiz Bello \\
\hline Carlos Murillo \\
\hline Cruz Pérez Cuéllar \\
\hline Hesiquio Trevizo \\
\hline Jaime García Chávez \\
\hline
\end{tabular}

Elaboración propia.

7 Dos casos que sirven de excelentes ejemplos son el del niño Rafael Santillán Vargas, de seis años, asesinado en agosto de 2018, y el de James Martin Camacho Padilla, niño de siete años, desaparecido en enero de 2018 y encontrado sin vida un mes después. 
Los colaboradores ${ }^{8}$ que escribieron los domingos de este mes $(2,9,16,23$ y 30 de septiembre de 2019), formaron un grupo constante; incluso a cada uno de sus textos se le asignó el mismo espacio y, es de suponerse, siempre con extensiones similares.

Lo que a continuación se presenta es el análisis de tres fragmentos que fueron elegidos tomando en cuenta tanto el contenido como la extensión, para que fuera posible el estudio comparativo. Las tres notas corresponden a tres autores distintos y aparecieron en el mismo mes entre los días 23 y 28; las tres tratan sobre el mismo hecho. Por último, el análisis se hace sobre notas aparecidas en el periódico impreso, no de su modalidad digital.

Respecto a la riqueza léxica, en la Tabla 5 se muestran los resultados obtenidos del análisis de los tres párrafos seleccionados. Esta riqueza es medible, o sea, es de naturaleza cuantitativa.

Tal como se muestra en esta tabla, el primer párrafo tiene una extensión de 124 palabras, el segundo 130 y el tercero 136. La cantidad de vocablos, es decir, eliminando las palabras repetidas, para el primero son 87, para el segundo 90 y para el tercero 94.

Primeramente, es necesario establecer los conceptos con los que se realiza el análisis y de los que se obtienen los resultados. Para medir la riqueza léxica, $\mathrm{N}$ equivale al total de palabras del texto que se examina; $V$ se refiere a la cantidad de palabras diferentes usadas en dicho texto; y el porcentaje es el producto de la división de $\mathrm{V}$ entre $\mathrm{N}$. Este índice es la proporción alcanzada entre

8 Es notorio el carácter parcial de tres de los colaboradores: Hesiquio Trevizo Bencomo es sacerdote, encargado de la parroquia Jesús Maestro ubicada en el fraccionamiento Córdova Américas; Cruz Pérez Cuéllar, por su parte y como es sabido, es un político mexicano que renunció al Partido Acción Nacional en el 2015 después de haberle sido suspendidos sus derechos dentro de dicho partido; por último, el autor de La vida de cuadritos es Andrés Molina Moreno (Santa Bárbara, Chihuahua, 1948), quien empezó a colaborar en este periódico desde el 2005. De los demás, a grandes rasgos se puede decir lo siguiente: Valero Flores es médico, dedicado al periodismo de opinión por más de 40 años en Durango y después en Chihuahua; Ortiz Bello fue de creador de imagen política a colaborador en periodismo de opinión por 20 años, e imparte clases en la UACH-CJ; Carlos Murillo pasó de militante priísta a opinador en los medios y a ser académico en la UACJ; García Chávez es opositor político desde la década de 1970, abogado litigante y colaborador en periodismo de opinión. 
Tabla 5. Medición de la riqueza en el uso de la lengua

\begin{tabular}{|cccc|}
\hline & Fragmento 1 & Fragmento 2 & Fragmento 3 \\
\hline Riqueza léxica & & & \\
\hline V/N & $87 / 124$ & $90 / 130$ & $94 / 136$ \\
\hline$\%$ & 70.16 & 69.23 & 69.11 \\
\hline Palabras nocionales & & & \\
\hline N/PN & $124 / 70$ & $130 / 75$ & $136 / 70$ \\
\hline$\%$ & .35 & .34 & .34 \\
\hline Hápax & & & \\
\hline & & & \\
\hline V/V1 & $124 / 66$ & $130 / 63$ & $136 / 79$ \\
\hline & .56 & .63 & .53 \\
\hline
\end{tabular}

Elaboración propia.

el número de palabras del texto analizado y el número de vocablos utilizados (palabras diferentes).

Un cálculo grueso es el que determina la proporción de vocablos (V). En este procedimiento es necesario dividir el total de vocablos $(\mathrm{V})$ entre el total de las unidades léxicas comprendidas en el texto (N) (ver Tabla 6).

Tabla 6. Indicador grueso de riqueza léxica

\begin{tabular}{|lll|}
\hline Fragmento 1 & $87 / 124=$ & .70 \\
Fragmento 2 & $90 / 130=$ & .69 \\
Fragmento 3 & $94 / 136=$ & .69 \\
\hline
\end{tabular}

Elaboración propia. 
La fórmula queda expresada de esta manera: $\mathrm{R}=\mathrm{V} / \mathrm{N}$ y se toman en cuenta todas las palabras según lo explicado por López Morales (1991, p. 18). Este índice nos ofrece una visión de diversidad léxica y sirve como indicador duro. Contrastando estos resultados con discursos de hablantes cultos notaríamos que estos últimos andan en el $0.5{ }^{9}$ esto nos indica que al disminuir la pendiente de la unidad, mayor riqueza léxica contiene un texto.

De acuerdo con López Morales, al cuantificar se procede con dos operaciones: "El recuento de las palabras que componen el texto y cuyo número [...] dará una medida de la extensión del texto, y [el] recuento de los vocablos empleados en el texto, y cuyo número [...] mide la extensión del vocabulario" (1991, p. 17). Así, un indicador grueso, según este autor, se obtiene con la fórmula $\mathrm{R}=(\mathrm{V} \times \mathrm{100}) / \mathrm{N}$; esto es, el total de vocablos (palabras diferentes) entre el total de unidades léxicas, o sea, palabras (la extensión). En nuestro caso queda como sigue:

$\begin{array}{ll}\text { Fragmento } 1 & (87 \times 100) / 124=70.16 \\ \text { Fragmento } 2 & (90 \times 100) / 130=69.23 \\ \text { Fragmento } 3 & (94 \times 100) / 136=69.11\end{array}$

Se deduce que, aunque el primer texto parece ser el de mayor riqueza léxica, este muestra que de 124 palabras escritas 87 fueron distintas. Sin embargo, comparándolo con el tercero, que contiene 94 palabras distintas, es decir, siete más que el primero, en extensión hay una diferencia entre ambos de doce palabras. Eso es delicado, pues indica que a mayor extensión mayor pobreza léxica. Supongamos que solo se analizan las primeras tres o cinco palabras de un enunciado, seguramente todas serían diferentes, pues es un tramo muy pequeño para encontrar repeticiones. Mas, cuando quien escribe se ve obligado a extender su texto, seguramente se enfrenta a un corto número de vocablos, lo cual lo inclinará a la repetición.

9 Este porcentaje se obtiene claramente de lo dicho por Justicia (1995): "el vocabulario que usan los hablantes adultos en la vida cotidiana no excede de las 2.000 palabras e incluso el de un hablante culto suele estar entre las 4.000 y 5.000 palabras diferentes" (Justicia citado por Carreres, 2015, p. 64). 
Otra medición establece el intervalo de aparición de los términos nocionales, palabras con carga semántica. Ese indicador considera la cantidad total de palabras del escrito y la divide por el conjunto formado por nombres, adjetivos y verbos, para obtener así el lapso de aparición en el texto de estas clases de palabras. Entonces, el índice aumenta conforme disminuya el intervalo de aparición de tales términos; por el contrario, cuanto más dilatado sea el intervalo, menor será la riqueza léxica de la muestra en cuestión. En otros términos, a mayor número de palabras nocionales, mejor índice de riqueza léxica. Se asume que las palabras nocionales representan la mitad del texto y en el análisis en cuestión podemos notar que no es esa la proporción.

Para el caso del cálculo de las palabras nocionales (estas refieren a los núcleos de la redacción, es decir, a las ideas ahí contenidas), $\mathrm{N}$ tiene el mismo equivalente, el total de palabras que se estudia; PN se refiere a las palabras nocionales, o sea, a las mencionadas categorías gramaticales (sustantivos, adjetivos y verbos). ${ }^{10} \mathrm{El}$ total de tales palabras fue el mostrado en la siguiente tabla:

Tabla 7. Palabras nocionales

\begin{tabular}{|l|l|}
\hline Fragmento 1 & $70 / 124$ \\
\hline Fragmento 2 & $75 / 130$ \\
\hline Fragmento 3 & $70 / 136$ \\
\hline
\end{tabular}

Elaboración propia.

Esta riqueza se mide en este caso con la fórmula de Giraud: $\mathrm{R}=\mathrm{V} / 2 \mathrm{~N}$. Él parte de la división de la cantidad de vocablos que aparecen en el texto entre el total de palabras que lo componen:

10 Por el contrario, las palabras con significado relacional equivalen al resto de las categorías gramaticales: artículos, preposiciones, conjunciones, adverbios, los pronombres que funcionan como nexos, incluso los verbos auxiliares (Bugueño Miranda, 2011, p. 11) 


$\begin{array}{ll}\text { Fragmento } 1 & 87 / 2 \times 124=.35 \\ \text { Fragmento 2 } & 90 / 2 \times 130=.34 \\ \text { Fragmento } 3 & 94 / 2 \times 136=.34\end{array}$

Este resultado es muy bajo si tenemos en cuenta "que Giraud asumía que las palabras nocionales representaban la mitad del texto" (Giraud citado por López Morales, 1991, p. 18), lo cual representa el factor 2 que multiplica al total de palabras.

Los productos en el caso de los tres textos nos dicen que los autores no alcanzan el porcentaje normal en la escritura, proporción establecida con los estudios de prestigiados lingüistas. ${ }^{11}$ Explica López Morales que "el resultado de esta operación matemática refleja cifras relacionadas con la proporción de palabras nocionales en el texto. Esto es, a mayor número de palabras nocionales, menor es el intervalo, lo que se interpreta como mejor índice de riqueza léxica” (1991, p. 20), dicho de otra forma, mientras mayor es el número de vocablos nocionales, mayor es la riqueza léxica.

Estos números que indican mayor o menor riqueza léxica están íntimamente ligados con los niveles de comprensión, la capacidad de razonamiento y la claridad de la expresión, o sea, el uso de los conceptos que expresan de una manera más adecuada una idea. De ahí que se exige claridad. Así, un texto es claro cuando se comprende, es decir, cuando el mensaje es comprendido sin dificultad por el destinatario. Tal claridad se logra con una expresión adecuada y correcta gramaticalmente, esto es, alternando oraciones simples y compuestas, con la concordancia sintáctica y el adecuado uso de los tiempos verbales; por eso se recomienda que se eviten vocablos ambiguos, se destierren los gerundios, se evite el exceso de adjetivos y, por supuesto, se evite el empleo de circunloquios o rodeo de palabras; en definitiva, que el mensaje no se preste a malentendidos o confusiones. Por otra parte, la capacidad que le permite a la persona conocer aquello que la rodea y entender las situaciones circunstanciales es una habilidad inte-

11 Entre los estudios más sólidos se pueden mencionar los de Giraud, Problemes et methodes de la statistique linguistique (1960); Müller, Estadística lingüística (1968) y Ham Chande, "Del 1 al 100 en lexicografía" (1979). 
lectual, que no solamente implica entender las palabras o frases, sino que consiste en captar de manera correcta el significado, en este caso, de un texto.

Por último, se revisan los hápax; según el diccionario de Real Academia Española (RAE) es la "voz registrada una sola vez en una lengua, en un autor o en un texto". Este porcentaje se obtiene dividiendo el total de palabras del texto entre el número de palabras utilizadas una sola vez. Es fácil deducir que entre mayor sea la muestra analizada, menor será este indicador, es decir, se encuentran más palabras usadas una y otra vez.

De acuerdo con lo dicho por Ramon Capsada Blanch y Joan Torruella Casañas, investigadores españoles:

Existen múltiples fórmulas de este tipo que se han ido proponiendo a través de los años, [...] Sin embargo, dos de ellas resultan bastante bien valoradas; son las medidas propuestas por Honoré y por Maas. [...] puede considerarse una medida de la riqueza léxica con una aceptable estabilidad y el más recomendable de los índices [...] cuanto mayor es su valor, menor es la riqueza léxica del texto analizado (2017, pp. 353-354).

Así pues, tomamos la fórmula de Maas: $\mathrm{R}=(\mathrm{N}-\mathrm{V}) / \mathrm{V} 1$. Este tipo de riqueza léxica se obtiene del número de total de palabras del texto que se analiza, menos el número de términos de vocablos (quitando los repetidos), entre el número de palabras de una ocurrencia. En el caso de estudio las operaciones quedan de la siguiente manera:

$\begin{array}{ll}\text { Fragmento } 1 & (124-87) / 66=.56 \\ \text { Fragmento 2 } & (130-90) / 63=.63 \\ \text { Fragmento 3 } & (136-94) / 79=.53\end{array}$

No olvidemos que cuanto más pequeño sea el índice, más riqueza léxica caracteriza al texto, pero conforme estos índices aumentan, la variedad léxica disminuye. Para tener un parámetro externo con el cual comparar esta riqueza de los fragmentos anali- 
zados, se puede mencionar el estudio que Maas realizó en la obra Curial y Güelfa (2007) de A. Ferrando, del que obtuvo un porcentaje/índice que oscila entre 0.19 y 0.2 (Maas citado por Capsada Blanch y Torruella Casañas, 2017, p. 354).

Hay otros aspectos en la redacción que al ser analizados aportan información acerca del uso de la lengua, por ejemplo, los enunciados gramaticalmente correctos (que toman en cuenta aspectos básicos: ortografía, acentuación y puntuación), las familias léxicas, campos semánticos o los asociativos, así como el sentido literal o figurado. Acerquémonos a los campos asociativos, herramienta muy útil a la hora de trabajar con estudiantes de gramática. Una palabra mantiene una relación con otras por lo siguiente: 1) por su relación con el referente (sustantivos de personas, de objetos, adjetivos y verbos); 2) por el procedimiento utilizado en la formación de palabras (derivación y composición); 3) por la estructuración de las familias de palabras o léxicas; 4) por su similitud ortográfica, es decir, por paronomasia; y 5) por la clase de relaciones establecidas entre palabras (sinonimia, antonimia y homonimia, hiponimia e hiperonimia, entre otras). ${ }^{12}$

En el caso de los campos asociativos el análisis no solo requiere de criterios morfológicos y sintácticos, sino que es obligado el estudio semántico ya que pasa la delgada línea entre palabras sueltas e ideas. Mientras que algunos paradigmas de palabras se agrupan en torno a la palabra central gracias a su identidad fónica, gráfica, de morfemas derivativos o léxicos, en los asociativos los términos se agrupan tanto por forma como por contenido, esto es, de significado. Por otra parte, ni siquiera estamos refiriéndonos a aspectos tan elementales como los vicios, las muletillas, las repeticiones y la gran cantidad de palabras vacías y frases de moda.

De todo ello se deduce que el dominio de la lengua materna requiere constancia y quien desee dedicarse a actividades en las que la lengua resulta ser la materia prima, está obligado a su estudio constante. Esta deducción no es exclusiva para nuestro entorno: ya en España Luis Alberto Hernando Cuadrado (2002), en

12 La explicación de los campos asociativos procede de la teoría de la "constelación asociativa" de Saussure (1965). 
su estudio titulado "Sobre la configuración lingüística del mensaje periodístico”, afirma que:

Dada la poderosa influencia ejercida por los medios de comunicación en la sociedad actual, el periodista debe esforzarse, ante todo, por presentar ante el público los hechos de una manera clara y objetiva. [...] En el esquema sintagmático, si bien es cierto que las palabras suelen sucederse con fluidez, siguiendo un orden en el que a lo puramente conceptual se superpone lo afectivo e imaginativo, y que los adjetivos muchas veces dotan de vitalidad a la expresión, se advierte una acusada tendencia al uso de epítetos tópico, circunloquios, secuencias y adverbios de relleno y redundancias (p. 74).

Damos por hecho que los periodistas asisten a los centros escolares y es ahí donde obtienen los conocimientos técnicos para dominar su profesión. Aunque Humberto López Morales afirma que "todo esto se aprende naturalmente desde los primeros años de enseñanza” (1991, p. 17), debemos agregar que el uso de la lengua se desarrolla durante los siguientes años (después del ambiente familiar se encuentran varios niveles escolares), siempre y cuando las circunstancias sean propicias.

Asimismo, Alberto Hernando García-Cervigón, otro investigador español, concluye en su artículo titulado "La lengua en el periodismo digital" que:

el uso que del código lingüístico se hace en el periodismo digital está marcado por unas notas que lo apartan en cierto modo del periódico tradicional impreso en papel, como resultado de las características inherentes al nuevo canal y de las exigencias del lector. Sin embargo, esta necesidad de adaptación a dicho canal no debe suponer que el periodista digital se centre sólo en intentar alcanzar un dominio absoluto de las nuevas tecnologías y de la forma de amoldar la lengua a esos condicionamientos, sino que debe seguir haciendo hincapié y persiguiendo el ideal de corrección y pulcritud idiomáticas, así como de perfección estilística que han guiado siempre al buen periodista (2003, p. 185). 
No olvidemos pues que la "calidad de la escritura" está integrada por una serie de factores, entre los que destacan la riqueza léxica y la madurez sintáctica. La amplitud y variedad del vocabulario tiene su fundamento en la disponibilidad léxica del hablante, y la madurez sintáctica, en su grado de entrenamiento combinatorial de oraciones simples y compuestas en el discurso; así pues, la coherencia discursiva depende esencialmente del "orden".

Insiste Hernando Cuadrado en que "debido a la rapidez con que se han de redactar muchas noticias o a la carencia de una sólida formación idiomática del redactor, de vez en cuando se detectan formas o estructuras gramaticales incorrectas o inadecuadas" (2002, p. 273). Sabido es que el vocabulario pasivo, o sea, el léxico, el conjunto de palabras que un individuo conoce como oyente, es mayor al vocabulario activo, es decir, a la cantidad de los términos que usa como hablante. Lo deseable en este asunto es motivar a los hablantes para que, por un lado, "pasen" las palabras que guardan en su cerebro, que sí conocen y que no usan, al conjunto de vocabulario activo; por otro, sería deseable que conozcan más palabras para ampliar ambos grupos, tanto el del léxico como el del vocabulario.

\section{EPÍLOGO}

En el año 2020, justo en el mes de abril, cuando fueron francas las circunstancias originadas con el virus que se extendió por el mundo, El Diario de Juárez entró en la curva de bajada con una pendiente muy pronunciada. Sin embargo, esa circunstancia solo fue azarosa, puesto que el periódico ya venía en picada, la contingencia sanitaria solo actuó de estocada. El ejemplar diario se redujo a la mitad de las páginas de la edición normal previa. Como consecuencia de lo anterior, se llevó a cabo una revisión en dicha empresa para reducir al máximo los gastos.

Entre las medidas tomadas, se despidió a un porcentaje muy alto de empleados, alrededor de 40 personas; además, a algunos se les disminuyó la cantidad de días laborales de 6 a 5 o a 4, según el caso lo ameritara; y a otros se les aumentó tanto la jornada 
como los días laborables, a 10 horas y a 7 días a la semana. Los criterios utilizados para tomar las decisiones fueron muy diversos, es decir, no fue un solo rasero. Para empezar, entre los directivos hubo una reducción del $25 \%$ de su salario. Por otro lado, empleados con varios años laborando fueron despedidos, mientras que otros, aunque con muy poca antigüedad (por lo cual saldría más barato liquidarlos) se quedaron. Ese es el caso del único corrector que existe ahí, quien junto con su superior realizan todo el trabajo; no era posible que se decidiera hacer a un lado a uno de ellos, pues uno solo no sacaría el trabajo; y aunque no hay corrección de interiores, habría un día sin corrección en absoluto. En rigor, todas las secciones se recortaron al 50\% grosso modo. Ninguna desapareció, más bien se fusionaron, por ejemplo, Economía con la Local y el Clasificado se añadió a Deportes.

Una situación curiosa es que los directivos no han mostrado interés en una bien pensada edición digital; se sabe que contratan expertos para que analicen y perfeccionen la publicación digital, sin embargo, el resultado ha dejado mucho que desear. En la edición digital trabaja muy poca gente y a pesar de que dicen que es el nuevo enfoque, el principal, lo cierto es que no se nota. Debemos agregar a lo anterior que no cuentan con reporteros para el área digital, ni correctores, ni un buen mantenimiento del sistema ni del sitio electrónico. Más bien, esa publicación electrónica les sirve para sacar pequeñas notas de última hora, de los hechos recién sucedidos, sobre todo de aquellos escandalosos, que pegan directo en el morbo del público o son del tema de moda. Hay un descuido absoluto de ello y en múltiples ocasiones no es cierta la información ahí plasmada, como sucedió con un terrible asunto acaecido el 3 de agosto de 2018 y que después "corrigieron" en las subsecuentes notas. Pero por lo pronto, el público ya leyó información errónea y seguramente un porcentaje de dichos lectores creyó lo que a través de ese medio se le dijo. ${ }^{13}$ El asunto se

13 El autor de tal nota fue un conocido periodista. Conviene recordar que él había hecho una declaración en el 2018: "No me voy a ir nunca a El Diario [...] Sé que algunos editores y jefes de El Diario temblarían con una confirmación o que me vieran caminando en los pasillos de la redacción, porque sé de sus pocas capacidades, pero no es mi intención (por lo menos en los siguientes 60 años). [...] Aclarado el punto, pueden 
agrava cuando se disminuye la presencia del medio impreso y el grueso de los lectores se queda en el digital, es decir, la influencia de quienes poseen tan bajo dominio léxico y gramatical son los que más están influyendo en el conocimiento del lenguaje vía las empresas periodísticas.

Las notas de este diario son siempre iguales: con el mismo lenguaje, el mismo ritmo, la misma información y el mismo lamentable desinterés absoluto en el gran esquema de cosas. Si el afán es meramente informativo, basta con poner "Se murieron 4 a balazos en calle Equis a las 4 pm. Se llamaban Juan, Víctor, José y Nabor". Pero si lo que se busca es el interés de la gente, más allá del hecho, se debe hablar de sus causas y su contexto. Una perspectiva diferente podría ser encontrada en los artículos de opinión, sin embargo, si somos honestos, quienes escriben dichos artículos no son mejores que quienes redactan las notas diarias. $\mathrm{Su}$ uso de la lengua es cotidiano, vulgar, dicho de otra manera, no se nota un cuidado en la elección y la combinación de las palabras. Es fácil deducir que en muchas de sus ideas expuestas falta investigación o que repiten las mismas obviedades una y otra vez. Es una tentación pensar que se suben al tren en automático para sacar su artículo semanal obligatorio, ya sea porque les cansa pensar o porque sus conocimientos no les da para ver las cosas desde otras perspectivas. Y aunque hay gente en la ciudad, poca, que escribe bien y que podría ser una voz autorizada para opinar sobre tal o cual asunto, primero están los amigos y si ese argumento no es suficiente ¿de quién es el periódico?

En Ciudad Juárez hay algunos problemas muy serios que requieren una solución urgente, entre ellos, es cierto, se encuentra un ambiente altamente violento que las autoridades no logran disminuir. Ese ambiente tiene sus raíces en diferentes circunstancias y no es un problema que haya nacido de la noche a la mañana; esas circunstancias se han ido acumulando desde hace varias décadas, yo diría incluso que desde hace alrededor de un siglo. 
Digo lo anterior porque bien sabemos que toda causa tiene una consecuencia, o viceversa.

Así que sería conveniente detenernos y revisar qué clase de empresas periodísticas en Ciudad Juárez son las que influyen en la lengua y, por lo tanto, en el pensamiento de sus lectores. Quizá sería momento de, como sostiene Gálvez Vera (2003), "la autorregulación periodística. [...] Reunirse periódicamente para analizar sus propias producciones y las de sus colegas, desde una perspectiva ética" (p. 149).

Si prestigiados autores, como Piaget y Vigotsky se preocuparon por la íntima relación entre lenguaje y pensamiento o pensamiento y lenguaje, sería oportuno que, entre las múltiples acciones que se pueden llevar a cabo en la búsqueda de encontrar soluciones que mejoren el ambiente social de Ciudad Juárez, se considere el papel que los periódicos juegan, ya que es indiscutible que tanto los diarios como las televisoras son medios que influyen en el lenguaje de los receptores, y por lo tanto, en el pensamiento, ya sea que lo estimulen o lo frenen.

Así visto y toda vez que es incuestionable que la lengua es el principal instrumento de los hombres de la prensa, provechoso sería que los propietarios de tales medios establecieran nuevas formas de contratación: exámenes de acentuación, de ortografía, de composición; realizar una entrevista sin hacer buen uso de la lengua es prácticamente imposible. De ahí que un periodista deba conocer muy bien su herramienta de trabajo, como un panadero debe conocer de harinas o un albañil de tipos de cemento. Las implicaciones en el uso de la lengua son muy delicadas, no se trata solo de la comprensión de una lectura, sino también de interpretaciones, de manipulación, de reflexión, hay cuestiones de fondo. Además de su trabajo de periodista, el individuo que labora en ese tipo de empresas también está fungiendo como profesor de lengua; por ello y sobre todo, no debe olvidarse la influencia del lenguaje en las capacidades cognitivas y cómo estas de un modo $\mathrm{u}$ otro repercuten en una cierta forma del ser sociable. 


\section{BIBLIOGRAFÍA}

Bugueño Miranda, F. V. (2011). Sobre las palabras y su clasificación según su contenido. Los problemas para el lexicógrafo, en Revista de Filología, núm. 29, enero, pp. 9-19.

Califano, B. (2015). Los medios de comunicación, las noticias y su influencia, en Revista mexicana de opinión pública, vol. 19, julio-diciembre, pp. 61-79.

Capsada Blanch, R. y J. Torruella Casañas. (2017). Métodos para medir la riqueza léxica. Revisión y propuesta, en Verba, vol. 47, pp. 347-408.

Carreres Lacasa, D. (2015). Valoración de repertorio léxico en español para escolares de 9 a 16 años (tesis), Castellón de la Plana, Universitat Jaume I, 275 pp.

Chomsky, N. (1979). Sintáctica y semántica en la gramática generativa, (trad., intr. y notas Carlos Peregrín Otero), México: Siglo XXI.

Hernando Cuadrado, A. (2002). Sobre la configuración lingüística del mensaje periodístico, en Estudios sobre el mensaje periodístico, vol. 8, pp. 261-274.

Escalante Gonzalbo, F. (2012). Crimen organizado, la dimensión imaginaria, en Nexos, núm. 418, octubre, pp. 32-44.

Febvre, L., y H-J. Martin. (1997). The Coming of the Book: The Impact of Printing, 1450-1800. London: Verso.

Gálvez Vera, J. L. (2003). Sensacionalismo, valores y jóvenes. El discurso y el consumo de dos periódicos bolivianos de crónica roja. La Paz: Universidad Autónoma Gabriel René Moreno.

García-Cervigón, A. H. (2003). La lengua en el periodismo digital, en Estudios sobre el mensaje periodístico, núm. 9, pp. 177-187.

Giraud, P. (1960). Problemes et methodes de la statistique linguistique, Paris: Presses Universitaires.

Ham Chande, R. (1979). Del 1 al 100 en lexicografía, en L. Fernando Lara (ed.), Investigaciones lingüísticas en lexicografía, México: El Colegio de México, pp. 110-132.

Lombana, L. y S. Valencia Treviño. (2000). Análisis semántico del léxico relacionado con la violencia utilizado en dos periódicos 
locales El País y El Caleño (tesis de licenciatura). Cali: Universidad del Valle, $131 \mathrm{pp}$.

López Morales, H. (1991). Los índices de riqueza léxica, en Actas del II Seminario Internacional sobre Aportes de la Lingüística a la Enseñanza del Español como Lengua Materna, San Juan: Editorial de la Universidad de Puerto Rico,.

Martínez Valencia, E. (2012). Análisis del léxico empleado en los titulares de la prensa popular colombiana, en ELUA, número 26, pp. 211-234.

Müller, C. (1968). Estadística lingüística, Madrid: Gredos.

Pansters, W. G. (2012). Zones of State-Making: violence, coercion, and hegemony in Twentieth-Century Mexico, en W. G. Pansters (ed.), Violence, Coercion, and State-Making in TwentiethCentury Mexico, Stanford: Stanford University Press.

Pétrovski, A. (1979). Psicología general. La Habana: Editorial Pueblo y Educación.

Piaget, J. (1954). Language and thought from the cognitive point of view, en P. Adams, Language in Thinking, U. K.: Penguin Books,

Piaget, J. (1976). El lenguaje y el pensamiento en el niño, (trad. M. Riani), Buenos Aires: Editorial Guadalupe.

Reyes Díaz, M. J. (2010). Riqueza léxica, en Anuario de Lingüística Hispánica. XXIII-XXIV (2007-2008), Universidad de Valladolid. Richmond, P. G. (1981). Introducción a Piaget, Madrid: Editorial Fundamentos.

Salas Alvarado, J. (2017). Factores que influyen en la creación y utilización de la jerga adolescente, en Káñina, Revista de Artes y Letras, Universidad de Costa Rica, XLI, núm. 2, septiembre-febrero, pp. 183-200.

Saussure, F. (1965). Curso de lingüística general, Buenos Aires: Alianza Editorial Losada.

Vygotsky, L. (2005). Pensamiento y lenguaje, (trad. José Pedro Rosaus Abadía), Barcelona: Editorial Paidós. 